\title{
Two Wire Pressure Transmitter using Bourdon Tube Pressure Sensor and LVDT - An Advance Pressure Transmitter
}

\author{
Subhashis Maitra \\ Electronics and Communication Engineering Dept. \\ Kalyani Government Engineering College \\ Kalyani, Nadia, West Bengal, India
}

\begin{abstract}
Bourdon Tube pressure Gauge is a mechanical type pressure transducer. Its display unit is a pointer attached with itself with a rack and pinion arrangement mounted at a spindle. Hence this cannot be used for remote measurement. Hence in order to measure the pressure sitting at the control station, a special measuring technique is to be adopted. The proposed technique, discussed in this paper, uses Linear Variable Differential Transformer (LVDT) and a two - wire transmitter and this can be used for reading the pressure of a process remotely. A ferromagnetic plunger type core is attached with the tip of the Bourdon Tube. The core here acts as a secondary sensing element which moves in an electromagnetic field generated by an excitation voltage in the primary of an LVDT. The movement of the ferromagnetic core with the movement of the tip of the Bourdon Tube generates an induced voltage in the secondary of the LVDT. The output of the LVDT is connected with a two-wire pressure transmitter to produce 4 - 20 milliampear corresponding to the pressure variation. The measurement of the current gives the pressure of the process with a good linearity and repeatability. The necessary theoretical equations along with the experimental results have been reported here clearly.
\end{abstract}

\section{Keywords}

Bourdon Tube, Ferromagnetic plunger type core, Primary coil, LVDT, Secondary coil, Secondary Transducer, Two wire Transmitter.

\section{INTRODUCTION}

Measurement of pressure is of considerable importance in process industries like, steel plant, medicine plant etc. where the pressure ranges from a little below atmosphere to several hundreds of atmospheres. For specifying pressures, three terms are generally used, namely absolute pressure, gauge pressure and vacuum. Absolute pressure is measured with respect to absolute vacuum. Gauge pressure is the difference between the absolute pressure and the atmospheric pressure. Whereas vacuum is defined as the negative gauge pressure. Manometers can indicate both absolute and gauge pressure but it has some disadvantages, such as low pressure measurement for the fluid which is evaporated at high temperature can interfere the measurement and compressible fluid may change the calibration of the measuring instrument and hence causing error. Force summing devices like, Diaphragms, Bellows, Bourdon tube gauge etc. can measure gauge pressure with significant accuracy. Among the force summing devices, Bourdon tube pressure gauge is one of the most important type pressure measuring device. Manometers and Bellows element gauges can measure pressure up to 0.1 Torr. Diaphragm gauges can measure pressure up to $10-3$ Torr. Bourdon tube pressure gauge can measure pressure up to $700 \mathrm{MPa}$ with approximate linearity. Vacuum measurement is classified into two types, electrical and mechanical types. Mechanical type includes McLeod gauge, Knudsen gauge etc. whereas electrical type includes Pirani gauge, Ionization gauge etc. McLeod gauge can measure vacuum up to $10-4$ Torr, whereas Pirani gauge can measure up to $10-3$ Torr. With the advancement of research, various pressure measuring instrument have been developed. Since most of the control systems operate with electrical signals, pneumatic pressure signal must be converted to current or voltage for monitoring or controlling purpose. Capacitive and resistive pressure transducers are commonly used for this purpose. Capacitive sensors sense the pressure in terms of the capacitance associated with the separation between the two plates (diaphragms) [1]. Whereas in case of resistive sensor, pressure is sensed in terms of the change in resistance caused by mechanically deforming the sensor [1]. Monocrystalline silicon pressure sensors [1] are being widely used in recent years. Though these types of sensors are manufactured based on semiconductor technology, they are operated based on the principle of resistive type sensors. The change in resistance in a monocrystalline semiconductor due to piezoelectric effect is higher than that in standard strain gauges. Conductivity in a doped semiconductor is influenced by an extremely small mechanical deformation and hence the sensitivity of monocrystalline sensors is higher than that of most other pressure sensors.

Now with the development of different pressure transducers [2],[3],[4], different techniques have been developed to measure pressure sitting at the control room which is located in a noise and hazard free atmosphere, far away from the process plant. That is, the pressures of the process sensed by the transducer at the plant site are to be transmitted to the control room for monitoring and controlling purpose. Two wire pressure transmitter is generally used for this purpose. The output of the two wire pressure transmitter may be pneumatic signal between 3 15 psi, voltage between $0-5 \mathrm{~V}$ or $0-10 \mathrm{~V}$ and current between $4-20 \mathrm{~mA}$ where the lower range corresponds to minimum pressure sensed and $20 \mathrm{~mA}$ corresponds to maximum pressure. These outputs of the pressure transmitter are not affected by the load impedance variation and supply voltage fluctuations. There are different types of pressure transmitters developed with the advancement of research. The output of pneumatic pressure transmitter 
[5],[6] such as flapper - nozzle assemble, is nonlinear. Linear range can be obtained from the normalized response curve for specific flapper movement and nozzle diameter [1]. Torque balance type transmitter [1], [7] consists of flapper nozzle, electromagnetic relay, feedback bellows, diaphragm and torque tube. Feedback bellows used here reduces the measurement error. Electrical type pressure transmitter [8], [9] consists of a comparator and an amplifier. Using this type of transmitter, better accuracy in pressure measurement can be achieved. Since Bourdon tubes [1], [10] can measure pressure in the range of almost $100,000 \mathrm{psi}(700 \mathrm{MPa})$, it can be used to measure pressure in process industries. In this paper, how industrial pressure can be measured and controlled using Bourdon tube, LVDT and two wire pressure transmitters[11],[12] has been explained clearly with experimental result. Also the response of the system for different excitation frequencies has been found experimentally. Section II explains the discussion on how a Bourdon tube in connection with an LVDT gives electrical output corresponding to specified range of pressure. Experimental results discussed in section III shows the importance of the proposed work. Section IV makes overall conclusions about the proposed work.

\section{PROPOSED TECHNIQUE}

The proposed work consists of three units, two of which are transducers and the other is a transmitter. The two transducers are Bourdon tube pressure gauge which is the primary transducer and LVDT which is the secondary transducer. Figure 1 shows the schematic diagram of a Bourdon tube. The tip of the tube is connected to a segmental lever through an adjustable link as shown in the Fig. The end of the segmental lever on the segment side is provided with a rack and pinion arrangement and mounted at a spindle. The lever is pivoted and the spindle holds the pointer as shown to provide a local indication of the measurement. A hair spring is used to fasten the spindle with the frame of the instrument to provide the necessary control torque. Due to the internal pressure, the near elliptic section of the tube tries to expand. The arrangement of the tube forces an expansion on the outer surface and a compression on the inner surface resulting the tube to unwind. This unwinding of the tube results an angular deviation ' $\Delta \emptyset$ ' over the total angular length ' $\varnothing$ '. For an applied pressure 'P', the relation of the angular deviation with the applied pressure is given by

$\mathrm{d}=\frac{0.05 \mathrm{P} \varnothing \alpha \mathrm{R}^{\frac{6}{5}}}{\mathrm{E} \beta^{\frac{1}{3}} \mathrm{t}^{\frac{3}{5}}}$

where, ' $\alpha$ ' and ' $\beta$ ' are the length of the major and minor axes of the elliptical tube, ' $t$ ' is the thickness of the tube material, ' $R$ ' is the radius of curvature of the tube and ' $E$ ' is the elastic modulus of the material.

The schematic diagram of an LVDT is shown in Figure 2(a) and (b). LVDT is a transducer which converts mechanical displacement into output electrical signal corresponding to the input displacement. It has three coils namely one primary and two secondary. Current in the primary coil induces e.m.f. on the two secondary. The induced e.m.f. depends on the difference of the mutual inductances of the primary and the secondary of the LVDT. The difference of mutual inductances again depends on the displacement of the core inside the LVDT. The output of LVDT is the difference between the two e.m.f.s induced on both the secondary since the two transducer secondaries are connected in opposition. At the center position of the measurement stroke, the two e.m.f.s induced on both the secondary are equal but because they are connected in opposition the resulting output from the sensor is zero. As the core moves away from the center, the result is an increase in one of the position sensor secondaries and a decrease in the other. This results in an electrical output corresponding to the input displacement whereas the phase of the output when compared with the excitation phase gives the direction of the movement of the core. The relationship between the input displacement and output voltage is given by the following equation $[1]$

$$
\operatorname{Eo}(j \omega) / \operatorname{Ei}(j \omega) / d(j \omega)=\frac{\omega \mathrm{kR}_{\mathrm{m}} /\left[\mathrm{R}_{\mathrm{p}}\left(\mathrm{R}_{\mathrm{s}}+\mathrm{R}_{\mathrm{m}}\right)\right]}{\sqrt{\left[\left\{1-\omega^{2}\left(\tau_{\mathrm{m}}^{2}+\tau_{\mathrm{p}} \tau_{\mathrm{s}}\right\}^{2}+\omega^{2}\left(\tau_{\mathrm{p}}+\tau_{\mathrm{s}}\right)^{2}\right]\right.}}
$$

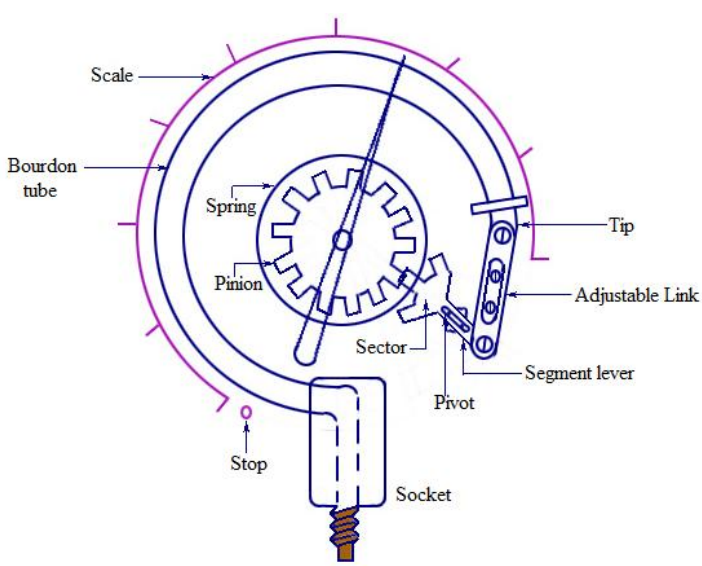

Fig. 1. Bourdon tube pressure gauge.

Where, $\tau_{p}=\frac{L_{p}}{R_{p}}, \tau_{s}=\frac{L_{s}}{\left(R_{s}+R_{m}\right)}, \tau_{m}^{2}=\frac{\left(M_{1}-M_{2}\right)^{2}}{\left\{R_{p}\left(R_{s}+R_{m}\right)\right\}}$ and $L p$, $\mathrm{Rp}, \mathrm{Ls}, \mathrm{Rs}, \mathrm{Rm}$ are respectively the primary inductance, the primary resistance, the secondary inductance, the secondary resistance and the meter resistance. M1 and M2 are the mutual inductances between the primary and the two half of the secondary. The phase angle between the input and the output is given by

$\varnothing=900-\tan ^{-1} \frac{\omega\left(\tau_{p}+\tau_{s}\right)}{1-\omega^{2}\left(\tau_{m}^{2}+\tau_{p} \tau_{s}\right)}$

Figure 3 shows the schematic diagram of the proposed pressure measurement unit consisting of the Bourdon tube and the LVDT. As shown in the Fig. the expanded adjustable link is used as the movable core of LVDT.

As the fluid under pressure enters the Bourdon tube, it tries to be reformed and because of the free tip available as shown in the Fig., this action causes the tip to travel in free space and the tube unwinds resulting a displacement of the adjustable link. The LVDT hence generates an electrical output as a function of the displacement of the adjustable link of the tube. The equivalent circuit of LVDT is shown in Figure 4, where the inter winding and the stray capacitances have been considered. 


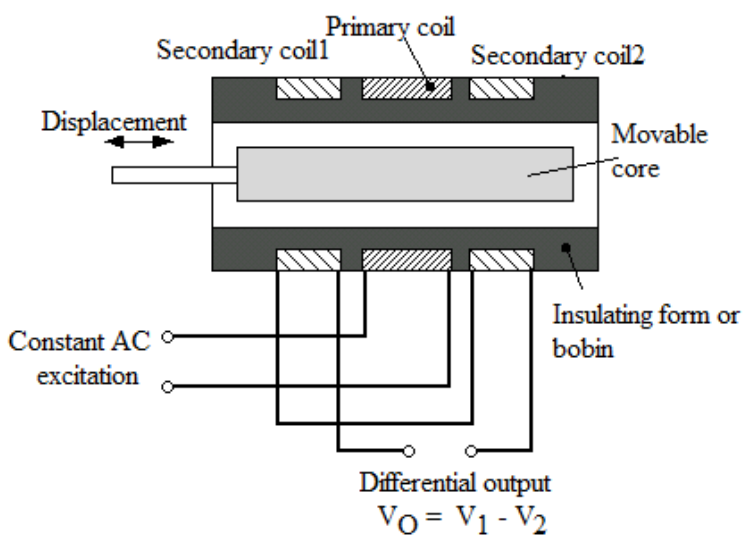

(a)

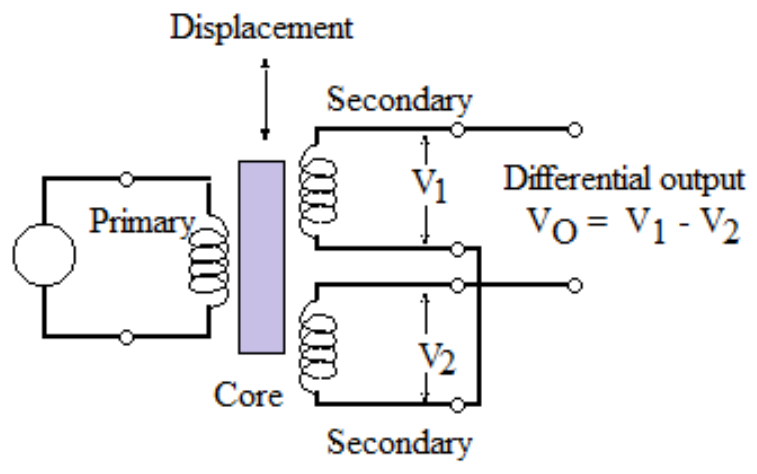

(b)

Fig. 2. Schematic diagram of LVDT.

In Fig., $\mathrm{Cp}$ and $\mathrm{Cs}$ are respectively the inter winding and the stray capacitance of the primary and the secondary.

Now, for the primary side,

$i p R p+\frac{1}{C_{p}} \int i_{p} d t+L p \frac{d i_{p}}{d t}+(M 2-M 1) \frac{d i_{s}}{d t}=e i$ (4)

and for the secondary side

is $(R s+R m)+\frac{1}{C_{s}} \int i_{s} d t+L s \frac{d i_{s}}{d t}+(M 1-M 2) \frac{d i_{P}}{d t}=0$

Now (4) and (5) can be written as

$\left(\mathrm{Rp}+\frac{1}{\mathrm{sC}_{\mathrm{p}}}+\mathrm{sLp}\right) \mathrm{ip}(\mathrm{s})-(\mathrm{M} 1-\mathrm{M} 2) \operatorname{sis}(\mathrm{s})=\mathrm{ei}(\mathrm{s})$ (6)

and

$\left[(\mathrm{Rs}+\mathrm{Rm})+\frac{1}{\mathrm{sC}_{\mathrm{s}}}+\mathrm{sLs}\right] \mathrm{is}(\mathrm{s})+(\mathrm{M} 1-\mathrm{M} 2) \operatorname{sip}(\mathrm{s})=0$ (7)

From (7), is $(s)=-\quad \frac{\left(M_{1}-M_{2}\right) s i_{p}(s)}{\left[\left(R_{s}+R_{m}\right)+\frac{1}{s C_{s}}+s L_{s}\right]}$ (8)

Substituting the value of is(s) in (6) and rearranging we get

$e i(s)=\left(R p+\frac{1}{s C_{p}}+s L p\right) i p(s)+\frac{\left(M_{1}-M_{2}\right)^{2} s^{2} i_{p}(s)}{\left[\left(R_{s}+R_{m}\right)+\frac{1}{s C_{s}}+s L_{s}\right]}$

$$
=i p(s)\left[R_{p}\left(R_{s}+R_{m}\right)+\frac{\left(R_{s}+R_{m}\right)}{s C_{p}}+s L_{p}\left(R_{s}+R_{m}\right)+\right.
$$

RpsCp+1s2CpCs+ LpCs+sLsRp+ LsCp+ s2LpLs+ ( M1- M2)2s2/ [Rs+ Rm+1sCs +sLs]

Now, eo(s) $=$ Rmis $(\mathrm{s})$

$$
=-\frac{R_{m}\left(M_{1}-M_{2}\right) s i_{p}(s)}{\left[\left(R_{s}+R_{m}\right)+\frac{1}{s C_{s}}+s L_{s}\right]}
$$

and $(M 1-M 2)=K d(s)$, where $d(s)$ is the Laplace of the displacement of the core in the field and $\mathrm{K}$ is a constant.

Hence,

$\frac{e_{0}(s)}{e_{i}(s) d(s)}$

$\frac{R_{m} K s}{R_{p}\left(R_{s}+R_{m}\right)+\frac{\left(R_{s}+R_{m}\right)}{s C_{p}}+s L_{p}\left(R_{s}+R_{m}\right)+\frac{R_{p}}{s C_{p}}+\frac{1}{s^{2} C_{p} C_{s}}+\frac{L_{p}}{C_{s}}+s L_{p} R_{p}+\frac{L_{s}}{C_{p}}+s^{2} L_{p} L_{s}+}$

$$
\left(M_{1}-M_{2}\right)^{2} s^{2}
$$

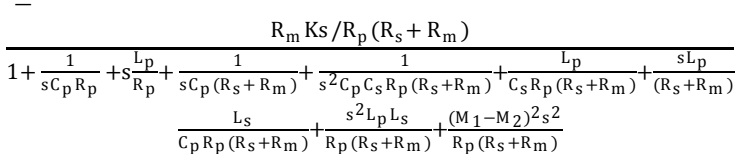

(9)

which gives

$$
\begin{aligned}
& \frac{e_{o}(j \omega)}{e_{i}(j \omega) d(j \omega)}= \\
& \begin{array}{c}
\left.\frac{R_{m} K s^{3} / R_{p}\left(R_{s}\right.}{}+R_{m}\right) \\
s^{2}+\frac{s}{\tau_{c p}}+s^{3} \tau_{l p}+\frac{s \beta}{\tau_{c p}}+\frac{1}{\tau_{c p} \tau_{c s m}}+\frac{s^{2} \tau_{l p}}{\tau_{c s m}}+s^{3} \tau_{p t s}+\frac{s^{2} \tau_{l s m}}{\tau_{c p}}+s^{4} \tau_{l p} \tau_{l s m} \\
+s^{4} \tau_{m}^{2}
\end{array} \\
& =\frac{R_{m} K j \omega^{3} / R_{p}\left(R_{s}+R_{m}\right)}{\left[\frac{1}{\tau_{c p} \tau_{c s m}}-\omega^{2}\left(1+\frac{\tau_{l p}}{\tau_{c s m}}+\frac{\tau_{l s m}}{\tau_{c p}}\right)+\omega^{4}\left(\tau_{l p} \tau_{l s m}+\tau_{m}^{2}\right)\right]+j\left[\frac{\omega}{\tau_{c p}}(1+\beta)\right.}
\end{aligned}
$$

where,

$$
\begin{gathered}
\tau_{c p}=C_{p} R_{p}, \tau_{l p}=\frac{L_{p}}{R_{p}}, \tau_{c s m}=C_{s}\left(R_{s}+R_{m}\right), \\
\tau_{l s m}=\frac{L_{s}}{\left(R_{s}+R_{m}\right)}, \tau_{p t s}=\frac{L_{p}}{\left(R_{s}+R_{m}\right)}, \beta=\frac{R_{p}}{\left(R_{s}+R_{m}\right)} \\
\text { and } \tau_{m}^{2}=\frac{\left(M_{1}-M_{2}\right)^{2}}{R_{p}\left(R_{s}+R_{m}\right)}
\end{gathered}
$$

Hence, the magnitude of (10) is

A

$$
\left|\frac{e_{o}(j \omega)}{e_{i}(j \omega) d(j \omega)}\right|=\frac{R_{m} K \omega^{3} / R_{p}\left(R_{s}+R_{m}\right)}{\sqrt{ }\left[\left\{\frac{1}{\tau_{c p} \tau_{c s m}}-\omega^{2}\left(1+\frac{\tau_{l p}}{\tau_{c s m}}+\frac{\tau_{\text {lsm }}}{\tau_{c p}}\right)+\omega^{4}\left(\tau_{l p} \tau_{l s m}+\tau_{m}^{2}\right)\right\}^{2}+\right.}+
$$

and phase angle between es and ei is

$\left\llcorner\varphi=900-\tan -1\left[\frac{\frac{\omega}{\tau_{\mathrm{cp}}}(1+\beta)-\omega^{3}\left(\tau_{\mathrm{lp}}+\tau_{\mathrm{pts}}\right)}{\frac{1}{\tau_{\mathrm{cp}} \tau_{\mathrm{csm}}}-\omega^{2}\left(1+\frac{\tau_{\mathrm{lp}}}{\tau_{\mathrm{csm}}}+\frac{\tau_{\mathrm{lsm}}}{\tau_{\mathrm{cp}}}\right)+\omega^{4}\left(\tau_{\mathrm{lp}} \tau_{\mathrm{lsm}}+\tau_{\mathrm{m}}^{2}\right)}\right]\right.$ 


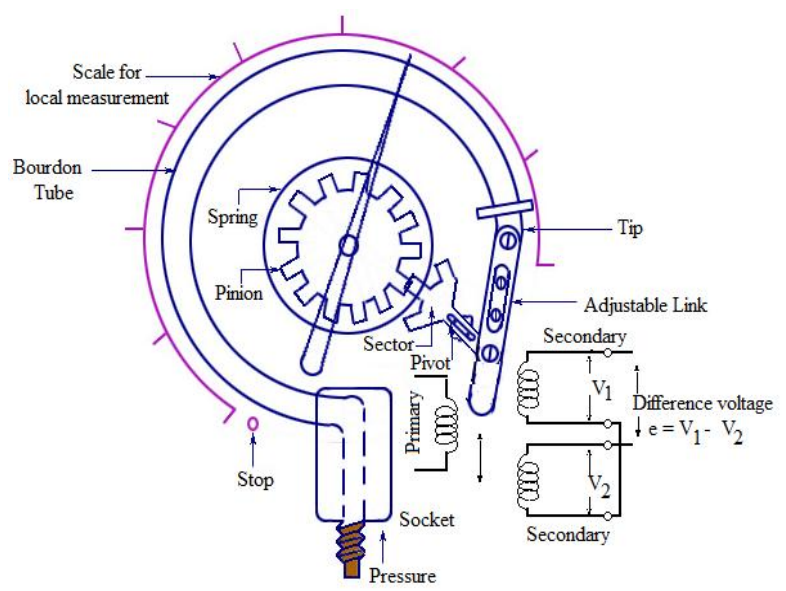

Fig. 3. Schematic diagram of the Pressure measurement unit.

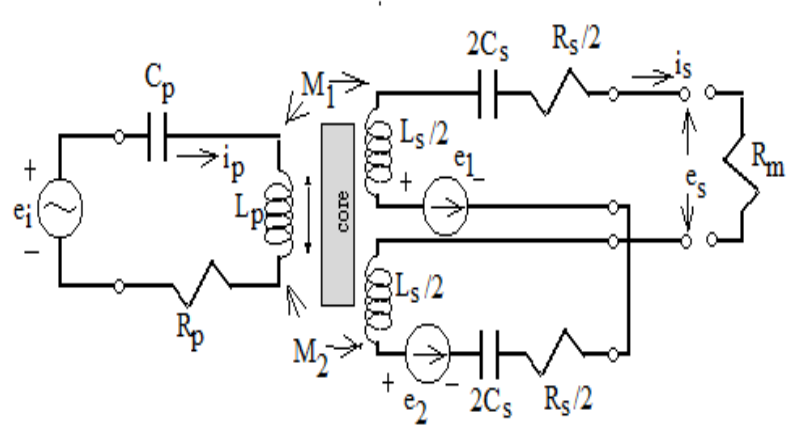

Fig. 4. Equivalent circuit of LVDT.

So the output of the LVDT is given by

$\mathrm{E}_{\mathrm{O}}=\mathrm{A}\left\llcorner\varphi \mathrm{E}_{\mathrm{i}} \mathrm{d}\right.$ and $\left|\mathrm{E}_{0}\right| \quad=\quad \mathrm{A}\left|\mathrm{E}_{\mathrm{i}}\right| \mathrm{d}$

(13)

It is seen from (11) and (12) that, both ' $A$ ' and ' $L \varphi$ ' vary with excitation frequency $(\omega)$. The variation of 'A' with ' $\omega$ ' is shown in Figure 5 for different values of the constant ' $\mathrm{K}$ '.

As it is seen clearly, the expression of the tip displacement is non-linear, however linearization may be done by mechanical means in this case. Figure 6 shows the variation of the tip displacement with the applied pressure. The Bourdon tube used in the proposed work is made up of Phosphor-Bronze whose modulus of elasticity is $15 \times 106$.

Now from (1) and (13), the output of the LVDT is

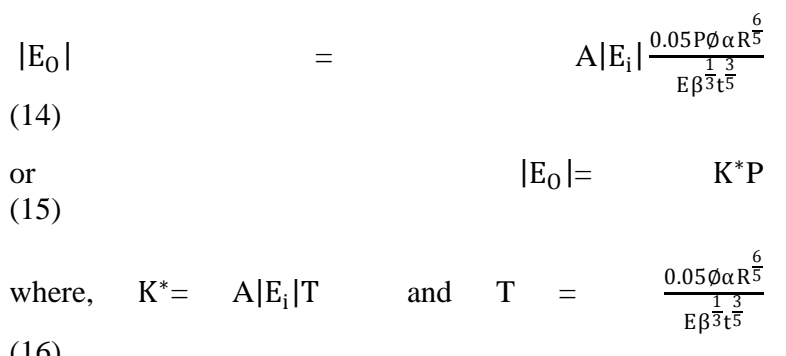

Typical ranges of the self and mutual inductances of the LVDT used here are given in Table 1 along with the values of the primary and secondary resistances and capacitances. The mutual inductances between the primary and the secondary vary with the core displacement and hence with applied pressure.

Table 1. Typical values of the inductances, resistances and capacitances both for primary and secondary of the LVDT used here

\begin{tabular}{|l|l|l|l|c|l|l|l|c|}
\hline $\mathrm{L}_{\mathrm{P}}$ & $\mathrm{M}_{1}$ & $\mathrm{M}_{2}$ & $\mathrm{~L}_{\mathrm{S} 1}$ & $\mathrm{~L}_{\mathrm{S} 2}$ & $\mathrm{C}_{\mathrm{P}}$ & $\mathrm{C}_{\mathrm{S}}$ & $\mathrm{R}_{\mathrm{P}}$ & $\mathrm{R}_{\mathrm{S}}$ \\
\hline 6 & $1-8$ & $1-8$ & 2 & 2 & 0.2 & 0.4 & 100 & 150 \\
$\mathrm{mH}$ & $\mathrm{mH}$ & $\mathrm{mH}$ & $\mathrm{mH}$ & $\mathrm{mH}$ & $\mu \mathrm{F}$ & $\mu \mathrm{F}$ & $\Omega$ & $\Omega$ \\
\hline
\end{tabular}

From the above table, the values of $\tau_{\mathrm{cp}}, \tau_{\mathrm{lp}}, \tau_{\mathrm{csm}}, \tau_{\mathrm{lsm}}, \tau_{\mathrm{pts}}, \beta$ and $\tau_{\mathrm{m}}$ can be calculated as shown in Table 2 considering $\mathrm{M} 1=8 \mathrm{mH}, \mathrm{M}_{2}=4 \mathrm{mH}, \mathrm{L}_{\mathrm{S}}=$ $4 \mathrm{mH}, \mathrm{R}_{\mathrm{m}}=200 \Omega$ and $\mathrm{d}=2 \mathrm{~mm}$.

Table 2. Values of different time constants and $\beta$

\begin{tabular}{|l|l|l|l|l|l|c|}
\hline $\begin{array}{l}\tau_{c p} \\
\mathrm{sec}\end{array}$ & $\begin{array}{c}\tau_{l p} \\
\mathrm{sec}\end{array}$ & $\begin{array}{c}\tau_{c s m} \\
\mathrm{sec}\end{array}$ & $\begin{array}{c}\tau_{l s m} \\
\mathrm{sec}\end{array}$ & $\begin{array}{c}\tau_{p t s} \\
\mathrm{sec}\end{array}$ & $\begin{array}{c}\tau_{m} \\
\mathrm{sec}\end{array}$ & $\beta$ \\
\hline $2 \mathrm{e}^{-5}$ & $6 \mathrm{e}^{-5}$ & $28 \mathrm{e}^{-5}$ & $1.12 \mathrm{e}^{-5}$ & $1.7 \mathrm{e}^{-5}$ & $2.05 \mathrm{e}^{-5}$ & 0.28 \\
\hline
\end{tabular}

So the value of $\mathrm{A}$ is $3.99 \times 10-8$, taking $\omega=50 \mathrm{~Hz}$ and $\mathrm{K}=$ 0.02 . Hence the output of the LVDT for $2 \mathrm{~mm}$ core displacement is $7.98 \times 100 \times 10-8=0.00007 \mathrm{mV}$, where $\mathrm{Ei}$ is taken as $100 \mathrm{~V}$. Now using (11), the ranges of the tip displacement for the input pressure range $1-1000$ bar (the range of pressure that the Bourdon tube used in the proposed work, can measure) can be calculated as $0.0019 \mathrm{~m}$ to $1.68 \mathrm{~m}$ for $\varnothing=2250, \mathrm{R}=0.2 \mathrm{~m}, \alpha=0.05 \mathrm{~m}, \beta=0.016$, $\mathrm{t}$ $=0.0015$ and $\mathrm{E}=15 \times 106$.

Figure 7 shows the variation of ' $\mathrm{K}^{*}$ ' for different values of ' $A$ ' and excitation voltages, i.e. the values of ' $\mathrm{K}^{*}$ ' vary linearly with ' $A$ ' and hence ' $\omega$ '. As shown in Fig. 7, the ranges of ' $\mathrm{K}$ ', are $(0.0006-0.5962) \times 10-12,(0.0002-$ $0.1789) \times 10-11$ and $(0.0004-0.3577) \times 10-11$. Figure 8 and Table 4 show the variation of the output voltage of LVDT with the process pressure for $\mathrm{A}=3.99 \times 10-8$ and $\mathrm{T}=$ $1.8633 \times 10-8$. Fig 8 shows that the output of LVDT varies linearly with process pressure using a linearizer.

The output of LVDT is then connected with a two-wire transmitter as shown in Fig. 9. Fig. 9 shows diagrammatically the method of experiment how the process pressure can be measured using the proposed system. The amplifier used in the experiment amplifies the electrical signal corresponding to the process pressure. In the signal conditioning stage, filter is used to filter out the noise present in the signal. The V/I converter used here as transmitter, converts the voltage signal corresponding to the pressure to $4 \mathrm{~mA}$ to $20 \mathrm{~mA}$ current signal, that is whatever the ranges of input pressure, the output of the transmitter will be $4 \mathrm{~mA}$ corresponding to the lowest and $20 \mathrm{~mA}$ corresponding to the highest process pressure. The output of LVDT is connected to the amplifier as shown to amplify the signal to the satisfactory level. The output of the amplifier is then passed to the signal conditioning stage which sets the upper and lower limit of the voltages that are to be measured or transmitted. V/I (voltage-to-current) converter converts the input voltage range to 4-20 mA. 


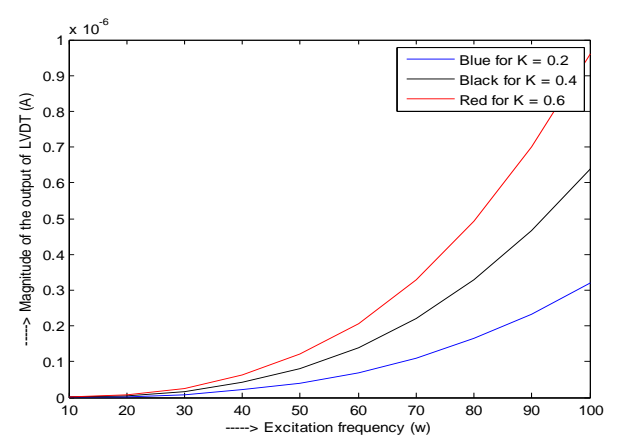

Fig. 5. Variation of ' $A$ ' with excitation frequency ' $\omega$ '.

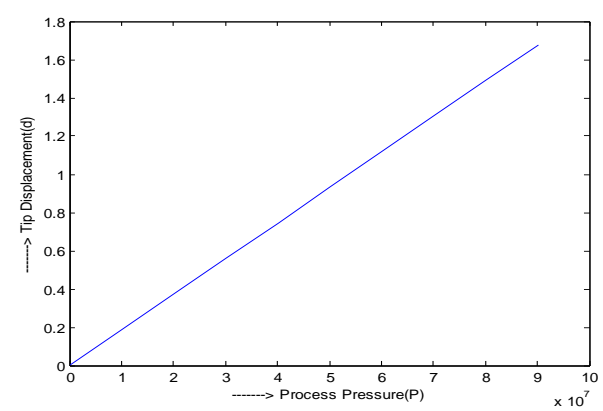

Fig. 6. Variation of tip displacement (d) with process pressure (P).

\section{EXPERIMENT AND RESULTS}

The specifications of the Bourdon tube, LVDT and twowire transmitter used in the proposed work are given in Table 3. The adjustable link of the Bourdon tube mentioned in Table 3 is expanded as shown in Fig. 3 in order to make it to move into the hollow pipe shaped LVDT. The output is then connected with the two-wire transmitter. Here, experiment has been conducted for pressure ranging from 1 bar to 10 bar and the corresponding displacements of the tip are noted. Due to the displacement of the tip inside the LVDT, the corresponding output voltages are also noted as shown in Table 4. The transmitter is set so that it gives 4 $\mathrm{mA}$ current for 1 bar applied pressure, where ' $\mathrm{K}$ ', ' $\omega$ ' and 'Ei' are taken as $0.2 \mathrm{mH} /$ meter, $50 \mathrm{~Hz}$ and $100 \mathrm{~V}$ respectively.

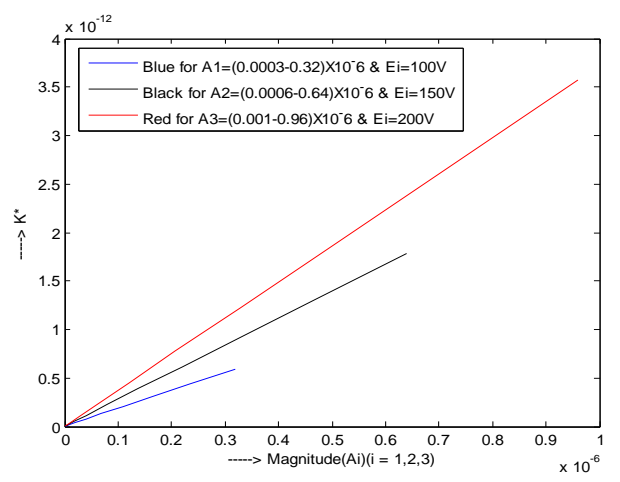

Fig. 7. Variation of $K *$ with ' $A$ ' and excitation voltage $\left(\mathbf{E}_{\mathrm{i}}\right)$.

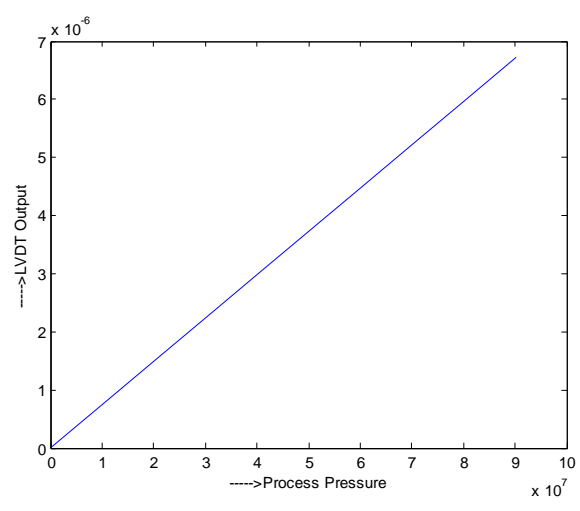

Fig. 8. Variation of the output of LVDT with process pressure (P).

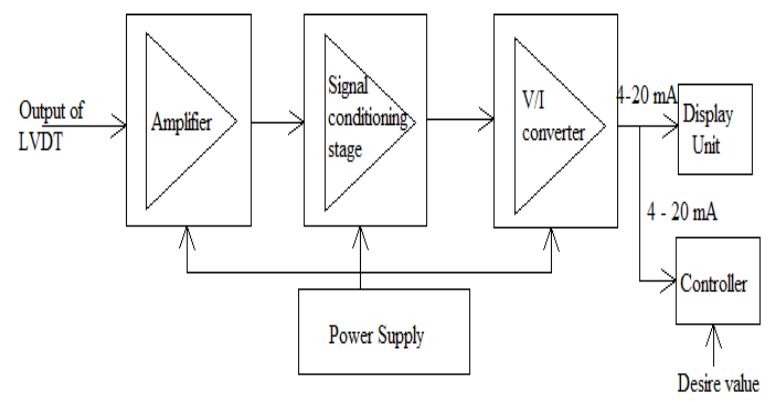

Fig. 9. Block diagram of the proposed remote measurement system.

\section{CONCLUSION}

The proposed pressure measurement system is useful to measure pressure both on spot and at remote place where control room is situated. Since the proposed system consists of Bourdon tube, it can be used for wide range of application. Table 4 shows that it provides less error. Since the output of the LVDT varies with excitation frequency and excitation voltage, these two are kept as constant in case of measurement, otherwise some nonlinear error may be incorporated in the measurement, since the amplitude of the output of LVDT varies nonlinearly with excitation frequency. Since the system consists of two-wire transmitter, no noise or electromagnetic interference may affect the measuring procedure.

Table 3. Specifications of the apparatus used in the experiment.

\begin{tabular}{|c|c|c|c|}
\hline & Range & Model no. & Accuracy \\
\hline $\begin{array}{l}\text { Bourdon } \\
\text { tube }\end{array}$ & $\begin{array}{l}0-1000 \\
\text { bar }\end{array}$ & $\begin{array}{l}\text { PBXSF100- } \\
\text { HD }\end{array}$ & $\pm 1 \%$ \\
\hline LVDT & $\begin{array}{l} \pm 1- \pm 10 \\
\text { inch }\end{array}$ & $\begin{array}{l}\text { XS-D } \\
\text { series } \\
\end{array}$ & $\pm 1 \%$ \\
\hline $\begin{array}{l}\text { Two-wire } \\
\text { mV } \\
\text { Transmitter }\end{array}$ & $\begin{array}{l}0-500 \\
\mathrm{mV}\end{array}$ & TT-230 series & $\begin{array}{l} \pm 0.05 \% \text { of } \\
\text { span }\end{array}$ \\
\hline
\end{tabular}


Table 4. Current output of the transmitter for the applied pressure ranging from $1 \mathrm{bar}$ to $10 \mathrm{bar}$.

\begin{tabular}{|c|c|c|c|c|}
\hline $\begin{array}{c}\text { Applied } \\
\text { pressure } \\
\text { in bar }\end{array}$ & $\begin{array}{c}\text { Displacement } \\
\text { of the tip in } \\
\text { meter }\end{array}$ & $\begin{array}{c}\text { Output } \\
\text { voltage of } \\
\text { LVDT in } \\
\text { mV }\end{array}$ & $\begin{array}{c}\text { Output } \\
\text { current } \\
\text { in mA }\end{array}$ & $\begin{array}{c}\% \\
\text { Error }\end{array}$ \\
\hline 1 & 0.0019 & 0.000076 & 4.1 & 2.5 \\
\hline 2 & 0.0037 & 0.0001 & 5.6 & 2.9 \\
\hline 3 & 0.0056 & 0.000224 & 7.3 & 2.9 \\
\hline 4 & 0.0075 & 0.0003 & 9.1 & 2.25 \\
\hline 5 & 0.0093 & 0.00037 & 10.8 & 2.5 \\
\hline 6 & 0.01 & 0.00039 & 13 & 2.7 \\
\hline 7 & 0.013 & 0.00052 & 14.3 & 2.2 \\
\hline 8 & 0.0149 & 0.00059 & 16 & 2.8 \\
\hline 9 & 0.0168 & 0.000672 & 17.5 & 2 \\
\hline 10 & 0.0186 & 0.00074 & 19.6 & 2 \\
\hline
\end{tabular}

\section{REFERENCES}

[1] D. Patranabis, Principles of Industrial Instrumentation (Second Edition), 2000, Tata McGraw-Hill Publication.

[2] H. E. Elgamel, "Closed-form expressions for the relationships between stress, diaphragm deflection, and resistance change with pressure in silicon piezoresistive pressure sensors", Sens. Actuators A, Phys., vol. 50, nos. 1-2, pp. 17 -22, 1995.

[3] K. Balasubramanian and A. Cellatoglu, "An inductive pickup for pneumatic pressure transducer developed over thin metallic spherical diaphragm”, in Proc. Int. Conf. Math. Comput. Sci., 2008, pp. $19-26$.

[4] A. Cellatoglu and K. Balasubramanian, "LVDT pickup for improved sensitivity in diaphragm based high-pressure measuring mechatronic device," in Proc. Int. Conf. Converg. Sci., Eng. Educ. Res., a Global Perspect. New Millennium, Bangalore, India, Apr. 2010, pp. IT_1-IT_5.
[5] A. Cellatoglu and K. Balasubramanian, "Dual capsule installed pneumatic pressure cell and pressure transmitter", in Proc., IEEE Symposium on Business, Engineering and Industrial Applications, 2011, pp(s). $475-480$.

[6] A. Cellatoglu and K. Balasubramanian, "Differential pressure transmitter with capacitive pickup installation", Proceedings of the International Conference on Electrical and Electronics Engineering and Computer Systems, Lefke, North Cyprus, Nov 2010, pp 11-15.

[7] H. Norton, "Transducer fundamentals," in Handbook of Transducers, Englewood Cliffs, NJ: Prentice Hall, 1989, ch. 2.

[8] R. Vrba, M. Sveda and K. Marecek, "Pressure transducer with multiplexed frequency transmitter", Proc. Sensors Ind. Conf.-SIcon, pp.7-10, 2004.

[9] B. D. Pereles, R. Shao , E. L. Tan and K. G. Ong, “A remote query pressure sensor based on magnetic higher order harmonic fields", IEEE Sensors J., vol. 8, no. 11, pp.1824-1829, 2008.

[10] S. C. Bera, N. Mandal and R. Sarkar, "Study of a pressure transmitter using an improved inductance bridge network and bourdon tube as transducer", IEEE Trans. Instrum. Meas., vol. 60, no. 4, pp.1453 -1460, 2011

[11] W. H. Ko, H. J., and B. S. F., "Development of a miniature pressure transducer for biomedical applications", IEEE Trans. Electron Devices, vol. ED26, pp.1896 -1905, 1979.

[12] E. O. Doebelin, Measurement Systems Application and Design, 1990, McGraw-Hill Publication 